\title{
The effects of basic gymnastics training integrated with physical education courses on selected motor performance variables
}

\author{
Ufuk Alpkaya \\ Marmara University, School of Physical Education and Sports, Istanbul, Turkey. \\ Accepted March 8, 2013
}

\begin{abstract}
The purpose of this study is the determine the influence of gymnastics training integrated with physical education courses on selected motor performance variables in seven year old girls. Subjects were divided into two groups: 1 , control group ( $N=15, X=7.56 \pm 0.46$ year old); 2, gymnastics group ( $N=16$, $X=7.60 \pm 0.50$ year old). The students in the control group followed the physical education curriculum for 10 weeks. The students in the gymnastics group took gymnastics training for 10 weeks in addition to physical education curriculum, and this training was given for two days (one hour each) at the university gym. Statistical analyses ( $t$ test) showed that basic gymnastics training improves selected motor tests like standing long jump, trunk lift, sit and reach, balance, run $20 \mathrm{~m}$, chin-up, curl-up, pushup $(p<0.05)$. Nevertheless, physical education classes alone did not affect these motor performance variables $(p>0.05)$, which were not expected.
\end{abstract}

Key words: Physical education, gymnastics training, children, motor performance.

\section{INTRODUCTION}

The purpose of physical education (PE) is to ensure comprehensive and harmonious development of children by developing and consolidating their motor abilities as well as helping them to gain the skills and experience useful in sport and everyday activities (Granacher et al., 2011; Piek et al., 2006; NASPE, 2005).

Various forms of motor activity play an essential role in the process of physical education (Lucertini et al., 2012; Haga, 2008). There is a large number of factors like physical activity that influence the growth and development of children (Malina et al., 2004; Lopes et al., 2011). The motor development and sports skills of pupils have been considered important in the PE curriculum (Haga, 2008). The importance of different forms of sports has been emphasized for pursuing life-long physical activity and for the versatile development of fitness and motor abilities (Pehkonen, 2004; Fujinaga, 2008; Gallahue and Ozmun, 2006). Motor ability can be conceptualized as a person's ability to execute different acts, including coordination of both fine and gross motor skills (Haga, 2008; Gallahue and Ozmun, 2006). Some of the existing motor tests typically focus on balance, flexibility, agility, speed, muscular strength and endurance (Fjortoft et al., 2011; Haga, 2008; Balas and Bunc, 2007).

Versatile exercise contents like gymnastics are highly suitable for the development of these characteristics (Pajek et al., 2010; Werner et al., 2012).

From the perspective of the child development, gymnastics is one of the key sports as any physical 
Table 1. Content of the gymnastics training program.

\begin{tabular}{llc}
\hline Practical content & & Time / Trials \\
\hline Warm - up & Mild running, jumping, rolling, calisthenic exercises & 10 min \\
Acrobatic Floor & Forward roll, backward roll, bridge, handstand (with teacher support). & 5 times \\
Vault & Split and squat jump on vault, forward roll. & 2 times \\
Mini /huge trampoline & Straight jump, split jump, tuck jump, half and full turns. & 2 times \\
Uneven bars & Leg lift in hang, swing in hang, half turn in support. & 2 times \\
Beam ( 5 meter long) & Walking on beam & 2 times \\
Cool down Stretching & Splits, sit and reach & 2times \\
\hline
\end{tabular}

exercise on the floor or apparatus that offers a great range of locomotive, stability and body control movements which are highly important for the development of children (Pajek et al., 2010).

Gymnastics requires a great diversity of movement; transitions from dynamic to static elements and vice versa, frequent changes of the body position in space (Culjak et al., 2003; Bressel et al., 2007).

In Turkey, PE classes do not contain gymnastics skills performed on apparatus but only some simple floor exercises. Generally, the PE curriculum focuses on ball games (such as basketball, football, handball, badminton, etc.), track and field activities and other games (Ministry of Education - Turkey, 2007).

However, most teachers would agree that gymnastics is an important activity for the healthy growth and development of children. In particular, gymnastics can promote the development of coordination, strength, muscular endurance, flexibility and balance (Werner et al., 2012; Bressel et al., 2007; Bencke et al., 2002).

Jeleska (2007) and Males et al. (2006) found that pupils who are in the PE classes and are regularly active in the sport branches show superior improvement in all motor abilities, compared to a group of pupils who attend only PE classes.

It is widely known that PE classes have positive impact on the children's motor performance (Fjortoft et al., 2011; Pehkonen, 2004; Kazimeirez and Ewa, 2010). However, it can be inferred that adding gymnastics to physical education classes would have a greater impact on the development of motor performance. For this reason, the aim of this study is to determine the effect of the 10 weeks gymnastics training integrated with physical education courses on selected motor performance variables of seven - year - old girls

\section{MATERIALS AND METHODS}

\section{Subjects}

Thirty one voluntary subjects were $7.58( \pm 0.48)$ year old girls, all of whom were second grade students at the same school, taking the same physical education course. The subjects were carefully chosen from among those who did not participate in a regular sports activity other than PE courses at school.
Before the study, participants and parents were given written information about the nature of the study. Written permission was obtained from the parents prior to their child's involvement in the study. Parents and the subjects were told that they were free to quit the test whenever they wanted. No child had any reported history of learning difficulties or any behavioral, neurological or orthopedic problems that would qualify as exclusionary criteria for this study.

The students were divided into two groups as control group $(\mathrm{N}=15, \quad \mathrm{X}=7.56 \pm 0.46$ year old) and gymnastics group $(\mathrm{N}=16$, $X=7.60 \pm 0.50$ year old).

\section{Procedure}

All applications and tests were carried out at the Marmara University gymnastics hall.

Control group: The students in the control group followed the PE curriculum for 10 weeks. In keeping with the PE curriculum, there was $2 \mathrm{~h}$ class per week (each class was $40 \mathrm{~min}$ ). The students were encouraged to participate in PE classes. Indeed, they were notified that those who would skip classes twice would be excluded from the research, but all students attended the classes regularly. Curriculum for March, April, and May included basketball, volleyball, handball, educational-athletic games, running and jumping. All students in this group were asked not to take part in a regular physical exercise program during the research.

Gymnastics Group: Students in this group took gymnastics training for 10 weeks in addition to PE curriculum, and this training was given for two days a week (one hour each) at the gymnastics hall. Their program is shown in Table 1.

Motor performance tests: The day before the test, the motor test battery was introduced to all the students, who did three test trials. The students were encouraged to show maximum effort in all tests. If a subject made a procedure error during the tests, instructions and demonstrations of the task were repeated, before the child made a new attempt.

Balance test: In this test, a dynamic balance test machine (Stability Platform Lafayette - 16020, IN USA) was used. The subject was asked to stand barefoot and keep his balance on the apparatus with the help of an assistant. After the prompt was given and the assistance was removed, the test began. The duration of the subject's maintenance of his balance was measured for $30 \mathrm{~s}$. The measurements were taken two times and the best value was recorded at the two attempts.

Sit and reach test (flexibility): sit and reach test apparatus was used to determine the trunk flexibility. Children were seated with the extended legs and the feet totally leaning in the seat. The subject tried to reach the largest distance slowly with the hands, without 
Table 2. Comparison of motor variables for gymnatics group between pre and post test.

\begin{tabular}{lcccccc}
\hline \multirow{2}{*}{ Variable } & \multicolumn{2}{c}{ retest } & \multicolumn{4}{c}{ Posttest } \\
\cline { 2 - 7 } & Mean & SD & Mean & SD & t & p \\
\hline Standing long jump (cm) & 111.70 & 13.10 & 119.72 & 12.46 & 6.76 & 0.012 \\
Trunk lift (cm) & 31.83 & 3.22 & 35.95 & 4.53 & 4.67 & 0.006 \\
Sit and reach (cm) & 11.75 & 3.29 & 17.89 & 3.68 & 9.65 & 0.000 \\
Balance (sec) & 16.93 & 3.69 & 20.68 & 3.65 & 5.54 & 0.000 \\
Run 20m (sec) & 4.86 & 0.70 & 4.37 & 0.41 & 3.91 & 0.002 \\
Chin up & 6.32 & 5.00 & 7.98 & 5.10 & 5.45 & 0.000 \\
Curl up & 21.84 & 7.30 & 25.44 & 7.44 & 3.32 & 0.004 \\
Push up & 9.33 & 5.21 & 10.78 & 5.32 & 3.46 & 0.005 \\
\hline
\end{tabular}

$\mathrm{p}<0.05$.

bending the legs. The measures were taken three times, with the best attempt recorded in centimeters.

Standing long jump (explosive strength): the child started with her feet in parallel behind a starting line, one shoulder width apart. After a signal the subject was allowed to swing her arms backwards and forwards and tried to jump as far as possible. The jump distance was measured in centimeters. The measures were taken two times and the highest value was recorded at the two attempts.

Curl up (muscular endurance): Child lied in a supine position on the mat, knees bent at an angle of approximately 140 degree, feet flat on the floor, legs slightly apart, with crossed arms in front of the chest. While the subject was in this position, an assistant held the subject's ankles. With the prompt, the subject was asked to assume a sitting position and touch her elbows to her knees. The subject's each move from and into the supine position was considered as one curl-up and the subject was asked to do as many times as she could. The maximum number of the curl-ups done by the subject was recorded.

Trunk lift (strength and flexibility): Child lied on the mat in a prone position. Toes are pointed and hands are placed under the thighs. Upon a signal the child lifted the upper body off the floor to a maximum height. The distance was taken from the floor to child's chin in centimeters. The measures were taken two times and the highest value was recorded.

Bent arm hanging (strength and endurance): The child was hung on the uneven bar with an overhand grasp with the assistant's support. She raised her body off the floor to a position in which the chin is above the bar; elbows were flexed and chest was close to the bar. Upon a signal, stopwatch was started and the hanging time was recorded.

Running 20 meters (speed): The child started in a standing position and run as fast as possible over 20 meters. The test score was the time required to run the distance (in seconds). If the child made a procedure error, the test was repeated. The measures were taken two times and the highest value was recorded.

Push - up (strength and endurance): The subject did a push - up position on the mat with hands placed wider than the shoulders; fingers stretched out and whole body went straight on the mat. Then the subject lowered the body using the arms until the elbows bent at a 90 degree angle, and upper arms were parallel to the floor. The subject pushed up and continued in the movement until the arms were straight on each repetition. The score was the number of 90 degree push - ups performed (The Cooper Institute,
2007).

To minimize the influence of the muscular fatigue and energy expenditure during the test, appropriate recovery among the same subject was made and a logical sequence for application was adopted.

\section{Statistical analysis}

Descriptive statistics (means and standard deviation) was calculated for all variables separately for each group. The independent variables in the study were the type of the groups. Paired t test (pre versus post) was performed to determine whether there were significant differences. All variables in each sample had normal disrubition which is tested by Kolmogorov - Smirnov test. There were no significant pretest differences between control and gymnastics group. Significant level was defined as $(p<0.05)$.

\section{RESULTS}

The means and standard deviations for each parameter are presented in Table 2. In the comparison of the motor tests for pre and post test scores in gymnastics group the followings are obtained: for standing long jump, $t=6.76$ $(p<0.01)$; trunk lift, $t=4.67(p<0.01)$; seat and reach, $t=9.65(p<0.01)$; balance, $(t=5.54, p<0.01)$; run $20 \mathrm{~m}$, $(\mathrm{t}=3.91, \mathrm{p}<0.01)$; chin up, $\mathrm{t}=5.45(\mathrm{p}<0.01)$; curl up, $\mathrm{t}=3.32$ $(p<0.01)$; push up, $t=3.46(p<0.01)$.

The means and standard deviations for each parameter are presented in Table 3. In the comparison of the motor tests for pre and post test scores in control group, the followings are obtained: for standing long jump, $t=0.305$ ( $p>0.05)$; trunk lift, $t=1.456$ ( $p>0.05)$; seat and reach, $t=0.201 p>0.05)$; balance, $t=0.051(p>0.05)$; run $20 \mathrm{~m}$, $t=0.325$ ( $p>0.05)$; chin up, $t=0.060$ ( $p>0.05)$; curl up, $t=0.624(p>0.05)$; push up, $t=1.477(p>0.05)$.

\section{DISCUSSION}

Strength, balance, coordination, speed, agility and flexibility are often described as performance related fitness, reflecting the performance aspect of physical fitness 
Table 3. Comparison of motor variables for control group between pre and post test.

\begin{tabular}{lcccccc}
\hline Variable & \multicolumn{2}{c}{ Pretest } & \multicolumn{4}{c}{ Posttest } \\
\cline { 2 - 7 } & Mean & SD & Mean & SD & t & p \\
\hline Standing long jump (cm) & 111.43 & 13.40 & 111.37 & 12.12 & 0.305 & 0.763 \\
Trunk lift (cm) & 31.46 & 3.43 & 30.59 & 3.30 & 1.456 & 0.365 \\
Sit and reach (cm) & 11.30 & 2.23 & 11.98 & 2.02 & 0.201 & 0.615 \\
Balance (sec) & 17.13 & 3.45 & 17.42 & 3.43 & 0.051 & 0.938 \\
Run 20m (sec) & 4.82 & 0.69 & 4.94 & 0.79 & 0.325 & 0.741 \\
Chin up & 7.48 & 4.87 & 8.01 & 2.42 & 0.060 & 0.079 \\
Curl up & 21.37 & 7.54 & 22.23 & 7.43 & 0.624 & 0.092 \\
Push up & 9.54 & 3.77 & 9.77 & 3.60 & 1.477 & 0.105 \\
\hline
\end{tabular}

$p<0.05$.

(Haga, 2008). Under the influence of physical exercise during growth and development, positive changes are expected especially in the area of motor abilities (Malina et al., 2004; Kazimeirez and Ewa, 2010). Motor competence has important implications for different aspects of development in children and adolescents (Piek et al., 2006).

In this study, pre-test and post-test measurements of all motor test batteries in the gymnastics groups show meaningful difference $(p<0.05)$, which means that the 10 weeks gymnastics training program for kids proved beneficial. On the other hand, it is significant that no statistically meaningful progress was seen in the control group ( $p>0.05)$.

It is a known fact that physical activities in PE classes improve children's motor abilities (Haga, 2008). The lack of meaningful motor performance can be attributed to the fact that our research duration was only 10 weeks, in which PE curriculum applied at the school may not have developed motor performance significantly. Similar to the findings, Jeleska (2007) and Males et al. (2006) indicated that pupils of 7 year - old who are in the PE classes and are regularly active in the sport branches (3 times a week) show superior improvement in all motor test parameters, compared to a group of pupils who attend only PE classes. In another study by Katic et al. (2002), it was reported that the exercise was effective on agility, coordination, balance, flexibility and aerobic endurance in younger school age.

After comparing a group of 7 year old girls, given judo training for 9 months, with a group who have not taken part in any sports, Krstulovic et al. (2006) observed improvement in the motor abilities (agility, static and dynamic muscular endurance, flexibility) of the first group.

Researching the effect of exercise only on balance, Perrin et al. (2002) compared how dance and judo trainings affect the balance and control groups with the aim to determine influences of individual training exercises on balance development. They found the judo players and dancers had significantly better values and increased sensory and motor adjustment. Another study by Aydın et al. (2002) and Bressel et al. (2007) have determined that balance development training increases the proprioception of the ankle and knee joints because it stimulates sensory and motor reaction.

Gymnastics offers a great range of locomotive, stability and body control movements which are highly important for the development of children. Gymnastics requires a great diversity of movement; transitions from dynamic to static elements and vice versa, frequent changes of the body position in space (Werner et al., 2012; Pajek et al., 2010).

Despite the lack of time devoted to gymnastics in schools' physical education programs, in the results of this study, it can be concluded that gymnastics classes integrated with physical education courses (independent from growth) cause positive changes in motor performance variables in 7 year - old girls. Precisely, ten weeks (twice a week) gymnastics training improved flexibility, explosive/static strength, muscular endurance, speed and balance parameters in kids. Nevertheless, eighty minutes - a week physical education courses alone was not enough to improve selected motor performance variables.

\section{REFERENCES}

Aydın T, Yildız Y, Yildız C, Atesalp S, Kalyon TA (2002). Proprioception of the ankle: a comparision between female teenage gymnasts and control. Foot Ankle Int. 23:123-129.

Balas J, Bunc V (2007). Short-term influence of climbing activities on strength, endurance and balance within school physical education. Int. J. Fit. 3(2):33-42.

Bressel E, Yonker CY, Kras J, Heath E (2007). Comporision of static and dynamic balance in female collegiate soccer, basketbaal, and gymnastics athletes. J. Athletic Train. 42(1):42-46.

Bencke J, Damsgaard R, Saekmose A, Jorgensen O, Jorgensen K, Klausen K (2002). Anaerobic power and muscle strength characteristics of 11 year old elite and non-elite boys and girls from gymnastics, team handball, tennis player and swimming. Scand. J. Med. Sports 12:171-178.

Culjak Z, Cavar M, Crnjac D, Maric K, Corluka M (2003). Effectiveness of the school of gymnastics in 7 years old children. Sport SPA. $8(8): 41-45$

Fjortoft I, Pedersen AV, Sigmundson H, Vereijken B (2011). Measuring physical fitness in children who are 5 to 12 years old with a test 
battery that is functional and easy to administer. Phys. Ther. 91(7):1087-1095.

Fujinaga $\mathrm{H}$ (2008). Static standing balance as a component of motor fitness among the 5-year- old children. Int. J. Fit. 4(2):67-74.

Gallahue DL, Ozmun JC (2006). Understanding Motor Development. Infants, adolescents, adults. ( $6^{\text {th }}$ ed.) USA: McGraw-Hill publication pp.69-88.

Granacher U, Muehlbauer T, Doerflinger B, Strohmeier R, Gollhofer A (2011). Promoting Strength and Balance in Adolescents During Physical Education: Effects of a Short-Term Resistance Training. J. Strength Cond. Res. 25(4):940-949

Haga M (2008). The relationship between physical fitness and motor competence in children. Child: care, health, and development. (5):329-334.

Jeleska K (2007). Utjecaj dodatnog kinezioloskog tretmanaverzalne sportske skole na neka antropoloskazja sedmogodisnjih djecaka I djewvojcica. $2^{\text {nd }}$ International Conference Contemporary Kinesiology, Mostar.

Katic R, Males B, Miletic D (2002). Effect of 6 month athletic training on motor abilities in seven- year- old girls. Colleglum Antropol. 26(2):533-538.

Kazimeirez K, Ewa K (2010). Body balance in children aged 11-13 years and the process of physical education. Pol. J. Sport Tourism 17:87-96.

Krstulovic S, Blazevic S, Karnincic H (2006). Promjene motorickih sposobnosti djevojcica tijekom devetomjesecnog judo purograma. $1^{\text {st }}$ international conference contremporariy kneniology. Kupres.

Lopes VP, Rodrigues LP, Maia JAR, Malina RM (2011). Motor coordination as predictor of physical activity in childhood. Scand. J. Med. Sci. Sports 21(5):663-669.

Lucertini F, Spazzafumo L, Lillo F, Centonze D, Valentini M, Federici A (2012). Effectiveness of professionally-guided physical education on fitness outcomes of primary school children. Eur. J. Sport Sci. 11(6):1-9.
Males B, Zuvela F, Katusic I (2006). Spolne razlike motorickih sposobnosti sedmogedisnje djece prije I nakon atketskog tretmana. Ist international conference contemporarly kinesiology, Kubres.

Malina RM, Bouchard C, Bar-Or O (2004). Growth, maturation, and physical activity. $\left(2^{\text {nd }}\right.$ ed.) USA: Human Kinetics Publication pp.47-53.

Ministry of National Education, Talim ve Terbiye Kurulu Başkanlığı (2007). Beden eğitimi dersi, (1-8) sınıflar öğretim programı ve kılavuzu. Türkiye pp.18-76.

NASPE (National Association for Sport and Physical Education) (2005). Physical Education for Lifelong Fitness. $\left(2^{\text {nd }}\right.$ ed) USA: Human Kinetics Publication pp.39-105.

Pajek MB, Cuk I, Kovac M, Jakse B (2010). Implementation of the gymnastics curriculum in the third cycle of basic school in Slovenia. Sci. Gym. J. 2(3):15-27.

Pehkonen M (2004). Qualty of the teaching process as an explanatory variable in learning gymnastics skills in school physical education. $M$. Qual. Teach. Proc. 2(2):29-40.

Perrin P, Deviterne D, Hugel F, \& Perrot C (2002). Judo, better than dance, develops sensory- motor adaptabilities involved in balance control. Gait Posture 15:187-194.

Piek JP, Baynam GB, Barett NC (2006). The relationship between fine and gross motor ability, self-perception and self-worth in children and adolescent. Hum. Mov. Sci. 25: 65-75.

The Cooper Institute (2007). Fitnessgram and Activitygram Test Administration Manuel. ( $4^{\text {th }}$ ed.) Human Kinetics Pub. pp.42-57.

Werner PH, Williams LH, Hall TJ (2012). Teaching Children Gymnastics. $3^{\text {th }}$ ed. Human Kinetics Pub. pp.23-38. 